\title{
Sigmoid colon perforation in the patient with granulomatosis with polyangiitis
}

\author{
Jun Iwabu', Tsutomu Namikawa1* , Hiroyuki Kitagawa', Toshichika Kanagawa', Junko Nakashima² \\ and Kazuhiro Hanazaki ${ }^{1}$
}

\begin{abstract}
Background: Granulomatosis with polyangiitis (GPA) induces respiratory tract and kidney granulomatous inflammation due to small-vessel vasculitis. However, gastrointestinal involvement, and especially colon perforation, is rare.

Case presentation: A 40-year-old man diagnosed with GPA was admitted to our hospital for GPA management. He was started on anti-cluster of differentiation 20 antibody (rituximab) therapy after admission and suffered severe abdominal pain 2 weeks later. A clinical diagnosis of sigmoid colon perforation was made, and we performed sigmoid colon resection with colostomy. Histopathological examination revealed loss of vascular wall and neutrophil infiltration. He was discharged from the hospital after intravenous immune globulin therapy.

Conclusions: Although gastrointestinal involvement is rare in GPA, severe complications require surgical intervention. Bowel perforation should be considered an important complication of GPA.
\end{abstract}

Keywords: Granulomatosis with polyangiitis, Sigmoid colon perforation, Gastrointestinal involvement

\section{Background}

Granulomatosis with polyangiitis (GPA, formerly known as Wegener's granulomatosis) is a systemic anti-neutrophil cytoplasmic antibodies-associated vasculitis that may result in life-threatening organopathies such as nephritis and pulmonary infiltration [1]. However, although there have been reports of colon perforation in GPA, gastrointestinal involvement is rare [2]. Here, we present a case of sigmoid colon perforation with GPA.

\section{Case presentation}

A 40-year-old Japanese man was referred to Kochi Medical School Hospital for treatment of GPA. The diagnosis of GPA had been made by symptoms of multiple lung nodule, otitis media, sinusitis, skin ulcer, and periocular granuloma 20 years ago. Furthermore, histopathological finding from skin ulcer revealed granulomatous vasculitis and blood examination showed positive of cytoplasmic anti-neutrophil cytoplasmic antibody (C-ANCA). He had been treated for GPA by his general practitioner

\footnotetext{
* Correspondence: tsutomun@kochi-u.ac.jp

${ }^{1}$ Department of Surgery, Kochi Medical School, Nankoku, Kochi 783-8505,

Japan

Full list of author information is available at the end of the article
}

with corticosteroids and methotrexate for 20 years. He was started on anti-cluster of differentiation (CD) 20 antibody (rituximab) and prednisolone combination therapy due to fever and advance of skin vasculitis, after admission to our hospital. Rituximab was injected day 1 (500 mg/body), and prednisolone was taken orally from day 1 to 14 (30 mg/body). Skin vasculitis had improved slightly; however, he suffered high-grade fever and severe abdominal pain at day 14 . Blood analysis revealed high levels of creatinine $(1.93 \mathrm{mg} / \mathrm{dL}$; normal range, $0.65-1.07$ $\mathrm{mg} / \mathrm{dL})$ and blood urea nitrogen $(24 \mathrm{mg} / \mathrm{dL}$; normal range, $8-20 \mathrm{mg} / \mathrm{dL}$ ). He was also found to have leukocytosis (white blood cell count, 30,200/ $\mu \mathrm{L}$; normal range, 3,300$8,600 / \mu \mathrm{L}$ ), a C-reactive protein level of $11.41 \mathrm{mg} / \mathrm{dL}$ (normal range, $<0.14 \mathrm{mg} / \mathrm{dL}$ ), and a procalcitonin level of $0.72 \mathrm{ng} / \mathrm{mL}$ (normal range, $<0.05 \mathrm{ng} / \mathrm{mL}$ ).

Computed tomography showed mesenteric emphysema of the sigmoid colon with inflammatory changes in the surrounding tissue (Fig. 1). After a clinical diagnosis of sigmoid colon perforation was made, we performed emergency surgery. During surgery, a sigmoid colon perforation of $3 \mathrm{~cm}$ in diameter was found. Although descending and sigmoid colon was edematous due to inflammation, there were no abnormal findings in the 

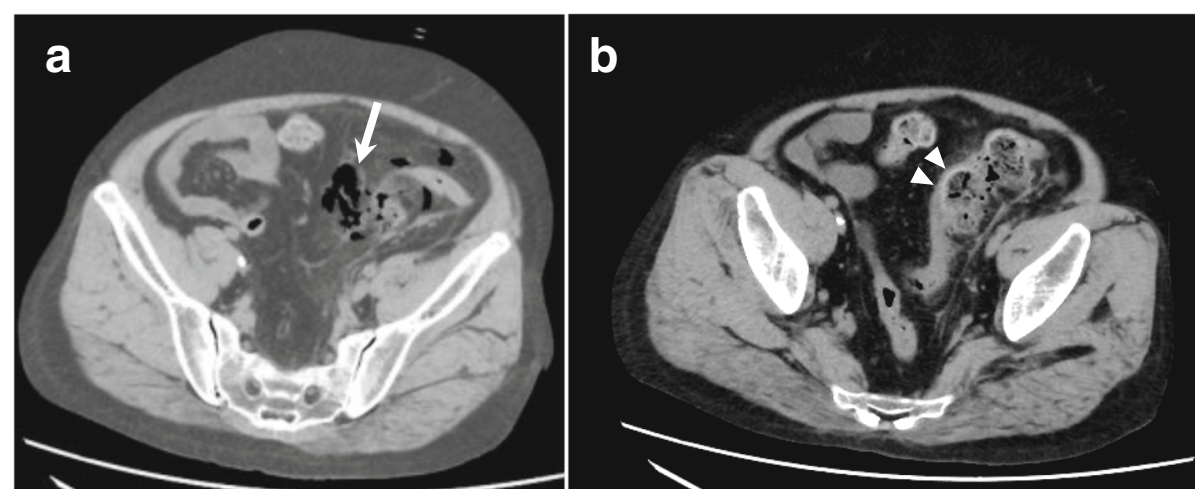

Fig. 1 Abdominal contrast-enhanced computed tomography showing a colonic perforation. Mesenteric emphysema (a, arrow) and inflammation (b, arrowhead) of the sigmoid colon are visible

other part of the colon and small intestine. Resection of $23 \mathrm{~cm}$ of sigmoid colon and rectum with colostomy formation was performed in accordance with Hartmann's approach (Fig. 2). Histological examination of the colon showed ulcerative lesions without cancer (Fig. 3a), and vessels around the ulcer showed loss of wall structures and neutrophil infiltration (Fig. 3b-d).

The patient had a postoperative complication of superficial surgical site infection, which was treated by opening, draining, and debriding the wound. After the wound healed, he was treated with intravenous immune globulin. He was discharged from our hospital 55 days after the emergency surgery with no other complications. The patient was asymptomatic and received medical treatment for GPA after the sixth postoperative month.

\section{Discussion}

GPA is characterized by necrotizing vasculitis and granulomatous inflammation. The disease is diagnosed based on findings of nasal or oral inflammation, nodules on chest radiographs, abnormal urinary sediment, and granulomatous inflammation on biopsy of the artery or perivascular area [3]. These findings are indicative of lifethreatening organopathies, such as nephritis and pulmonary infiltration. However, gastrointestinal involvement of GPA is rare, with a reported incidence rate of $5-11 \%$ [4].
There is published literature on gastrointestinal involvement in systemic necrotizing vasculitis. Earlier reports showed that GPA patients presented with diarrhea, hematochezia, and gastrointestinal ulcers [5-7]. Pagnoux et al. reported the outcome of gastrointestinal involvement in 62 patients with systemic necrotizing vasculitis which include GPA, polyarteritis nodosa, Churg-Strauss syndrome, microscopic polyangiitis, and rheumatoid arthritis-associated vasculitis [5]. In their report, 9 of 62 patients (15\%) had bowel perforation; however, there was no patient with GPA in 9 patients and the longest interval from diagnosis in their cohort was only 68 months. Furthermore, less than 20 cases of bowel perforation associated with GPA were reported in published literature in English [8-21]. Table 1 shows the clinicopathological features of the 15 reported cases [8-21] as well as those of the present case. The median patient age was 44 years (range, 19-69 years), and the male-tofemale ratio was 11:4. The reported perforation sites were the jejunum in 2 cases, the ileum in 10 patients, and the colon in 4 patients. Histological analysis of the lesions revealed 9 and 4 instances of vasculitis and ulceration, respectively. To the best of our knowledge, ours is the second case of isolated colon perforation. There were no reports about colon perforation with GPA patients after rituximab administration without our patient.
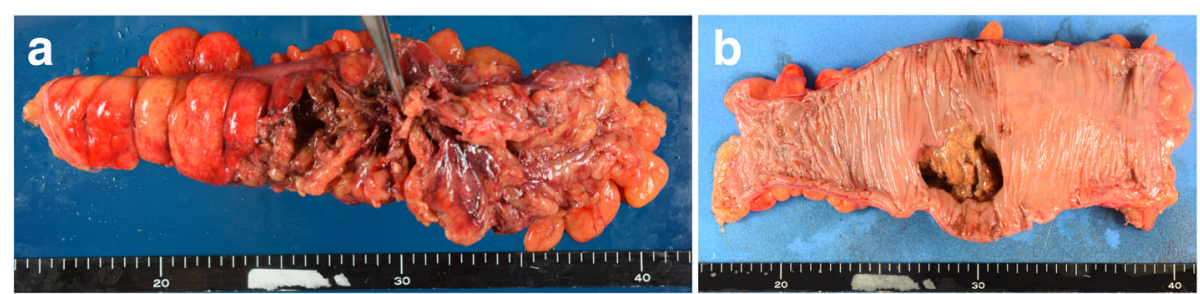

Fig. 2 Macroscopic appearance of the resected specimen. The surface of the serosal side showed edematous due to inflammation (a). The surface of the mucosal side shows a perforation of $4 \mathrm{~cm}$ in diameter. The mucosae around the perforation site are intact without ischemic change (b) 

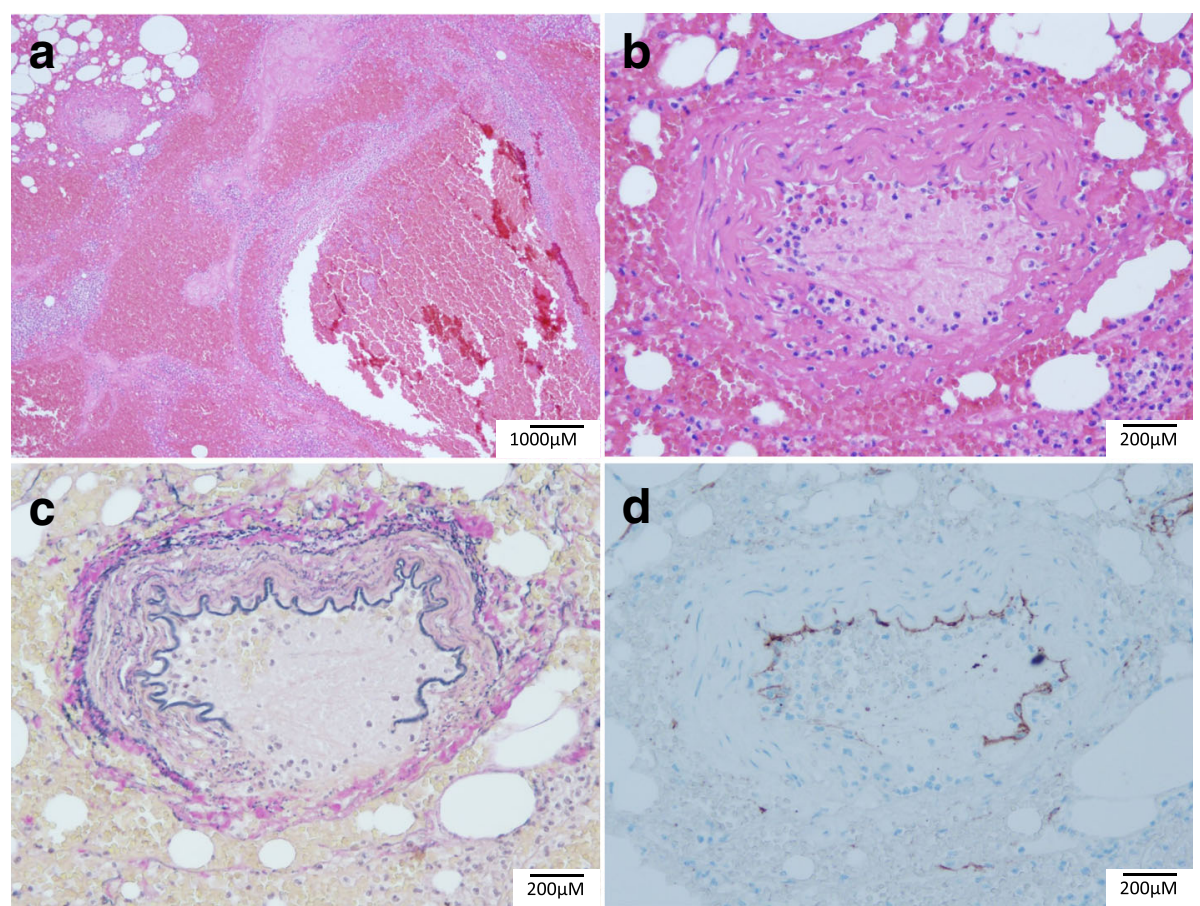

Fig. 3 Pathological findings of the resected specimen. Histological sample of the colon shows ulcerative lesions and fibrinoid necrosis (a, hematoxylin and eosin $[\mathrm{HE}]$ staining, $\times 40)$. Fibrinoid necrosis and neutrophil infiltration of the small vessel $(\mathbf{b}, \mathrm{HE}$ staining, $\times 200)$ and loss of vascular wall (c, Elastica van Gieson staining, $\times 200$; d, cluster of differentiation 34 staining, $\times 200$ ) are demonstrated

Furthermore, previous reports indicate that gastrointestinal symptoms tend to occur within 5 years of the initial diagnosis. In our patient, sigmoid colon perforation occurred 20 years after the initial diagnosis. This case may be categorized as another specific colon perforation group with GPA in terms of long treatment period and rituximab administration.

A plausible reason for the perforation is the advanced nature of the polyangiitis. We investigated the histopathological findings that were not contradictory to the

Table 1 Reported cases of intestinal perforation associated with granulomatosis with polyangiitis

\begin{tabular}{|c|c|c|c|c|c|c|}
\hline Reference & Age/sex & Perforation site & Disease duration (months) & Drug & Pathology & Prognosis \\
\hline Our case & $40 / \mathrm{M}$ & Colon & 240 & $P+M+R$ & Vasculitis & Survival \\
\hline Toh et al. [8] & $19 / F$ & Small bowel & 1 & $P+R$ & Vasculitis & Survival \\
\hline Akbulut [9] & $47 / M$ & Ileum & 18 & $P+C$ & NS & Death \\
\hline Samim et al. [10] & $35 / M$ & Jejunum & 4 & $P+C$ & Ulceration & Survival \\
\hline Yildirim et al. [11] & $32 / \mathrm{M}$ & Ileum & 0.5 & $P+C$ & Vasculitis & Death \\
\hline Deniz et al. [12] & $44 / \mathrm{M}$ & Ileum & 1 & NS & Vasculitis & Survival \\
\hline Shaikh et al. [13] & $44 / F$ & Ileum, colon & 2 & $P$ & Vasculitis & Survival \\
\hline Strivens et al. [14] & $54 / F$ & Ileum, colon & 1.5 & $P+C$ & Vasculitis & Survival \\
\hline Akca et al. [15] & $56 / \mathrm{M}$ & Ileum & 3 & $P+C$ & Ulceration & Survival \\
\hline Skaife at al. [16] & $69 / M$ & Jejunum & 0.2 & $P+C$ & NS & Death \\
\hline Srinivasan and Coughlan [17] & $56 / F$ & Ileum & 1 & $P+C$ & Vasculitis & Survival \\
\hline Storesund et al. [18] & $26 / M$ & Colon & 18 & $P+C$ & Vasculitis & Survival \\
\hline Tokuda et al. [19] & $37 / M$ & Ileum & 24 & $P+C$ & Vasculitis & Survival \\
\hline Geraghty et al. [20] & $46 / \mathrm{M}$ & Ileum, colon & 1 & $P+C$ & Ulceration & Death \\
\hline McNabb et al. [21] & $50 / \mathrm{M}$ & Ileum & 9 & $P+A$ & Ulceration & Survival \\
\hline
\end{tabular}

$P$ prednisolone, $M$ methotrexate, $R$ rituximab, $C$ cyclophosphamide, $A$ azathioprine, $N S$ not stated 
diagnosis of GPA using Elastica van Gieson and CD34 staining protocols. The prognosis of GPA has improved with effective induction therapy using corticosteroids combined with cyclophosphamide or rituximab, with 5year survival rates $>80 \%$ [22]. Therefore, careful examination at follow-up with emphasis on assessing possible gastrointestinal involvement is necessary for GPA patients over the long term.

Another likely reason for the perforation is the effect of rituximab. There are no reports of bowel perforation following rituximab administration. However, there are reports of bowel perforation associated with rituximab in post-transplant lymphoproliferative disorder [23, 24]. In 2006, Roche Pharmaceuticals issued a warning regarding the risk of intestinal perforation following rituximab administration.

Compared to previous reported cases, the interval from GPA diagnosis to colon perforation was exceptionally long. Former colon perforation cases with GPA patients might be involved in granulomatosis strongly. In our patient, long-term corticosteroids and methotrexate administration might have contributed to the weakness and thinning of the intestinal wall. The colon perforation was likely to be occurred by combination of intestinal wall weakness, GPA progression, and rituximab administration.

To avoid severe gastrointestinal complications in GPA patients, it is crucial that severe abdominal symptoms are not missed. Especially when GPA progression or rituximab administration starts, it is important to beware of symptoms such as high grade and severe abdominal pain. Gastrointestinal perforation should be regarded as an important complication of GPA.

\section{Conclusions}

GPA with sigmoid colon perforation is rare, but early diagnosis and rapid treatment are necessary when it occurs.

\section{Abbreviations}

CD: Cluster of differentiation; GPA: Granulomatosis with polyangiitis

\section{Acknowledgements}

We would like to thank Editage (www.editage.jp) for English language editing.

\section{Authors' contributions}

$\mathrm{JI}$ and TN contributed to the writing of the manuscript. $\mathrm{KH}$ supervised the study. Jl, HK, and TK served as the attending physicians of the presented patient. JN contributed to the pathological diagnosis. All authors read and approved the final manuscript.

\section{Funding}

None

\section{Ethics approval and consent to participate}

This study was conducted in accordance with the principles of the Declaration of Helsinki.

\section{Consent for publication}

The patient gave consent for the publication of images.

\section{Competing interests}

The authors declare that they have no competing interests.

\section{Author details}

'Department of Surgery, Kochi Medical School, Nankoku, Kochi 783-8505, Japan. ${ }^{2}$ Laboratory of Diagnostic Pathology, Kochi Medical School Hospital, Nankoku, Kochi, Japan.

Received: 6 March 2019 Accepted: 20 May 2019

Published online: 30 May 2019

\section{References}

1. Lutalo PM, D'Cruz DP. Diagnosis and classification of granulomatosis with polyangiitis (aka Wegener's granulomatosis). J Autoimmun. 2014;48-49:94-8.

2. Watts RA, Lane SE, Bentham G, Scott DG. Epidemiology of systemic vasculitis: a ten-year study in the United Kingdom. Arthritis Rheum. 2000;43: 414-9.

3. Leavitt RY, Fauci AS, Bloch DA, Michel BA, Hunder GG, Arend WP, Calabrese LH, Fries JF, Lie JT, Lightfoot RW Jr, Masi AT, MsShane DJ, Mills JA, Stevens MB, Wallace SL, Zvaifler NJ. The American College of Rheumatology 1990 criteria for the classification of Wegener's granulomatosis. Arthritis Rheum. 1990:33:1101-7.

4. Pinkney JH, Clarke G, Fairclough PD. Gastrointestinal involvement in Wegener's granulomatosis. Gastrointest Endosc. 1991;37:411-2.

5. Pagnoux C, Mahr A, Cohen P, Guillevin L. Presentation and outcome of gastrointestinal involvement in systemic necrotizing vasculitides: analysis of 62 patients with polyarteritis nodosa, microscopic polyangiitis, Wegener granulomatosis, Churg-Strauss syndrome, or rheumatoid arthritis-associated vasculitis. Medicine (Baltimore). 2005;84:115-28.

6. Latus J, Koetter I, Fritz P, Kimmel M, Biegger D, Ott G, Stange FE, Amann K, Alscher DM, Braun N. Gastrointestinal involvement in granulomatosis with polyangiitis and microscopic polyangiitis: histological features and outcome. Int J Rheum Dis. 2014;17:412-9.

7. Masiak A, Zdrojewski Ł, Zdrojewski Z, Bułło-Piontecka B, Rutkowski B. Gastrointestinal tract involvement in granulomatosis with polyangiitis. Prz Gastroenterol. 2016;11:270-5

8. Toh JWT, Fehlberg T, Raashed S, Patapanian H, Turner C. Unexpected bowel perforation in Wegener's granulomatosis. ANZ J Surg. 2018;88:245-7.

9. Akbulut S. Multiple ileal perforations in a patient with Wegener's granulomatosis: a case report and literature review. J Gastrointest Surg. 2012:16:857-62.

10. Samim M, Pronk A, Verheijen PM. Intestinal perforation as an early complication in Wegener's granulomatosis. World J Gastrointest Surg. 2010; 2:169-71.

11. Yildirim AC, Koçak E, Yildiz P, Yildiz M, Karakayali AS, Kaptanoglu B, Köklü S. Multiple intestinal perforation in a patient with Wegener's granulomatosis: a case report and review of the literature. Gastroenterol Clin Biol. 2010;34: $712-5$.

12. Deniz K, Ozseker HS, Balas S, Akpinar E, Sökmensüer C. Intestinal involvement in Wegener's granulomatosis. J Gastrointestin Liver Dis. 2007; 16:329-31.

13. Shaikh FM, Sabu CB, Peirce TH, Naqvi SA. Extensive intestinal ischaemic necrosis in Wegener's granulomatosis. Gut. 2006:55:1368-9.

14. Strivens RL, Bateman A, Arden NK, Edwards CJ. Intestinal perforation and jejunal hemorrhage due to Wegener's granulomatosis. Clin Exp Rheumatol. 2005;23:124

15. Akça T, Colak T, Cağlıkülekçi M, Ocal K, Aydin S. Intestinal perforation in Wegener's granulomatosis: a case report. Ulus Travma Acil Cerrahi Derg. 2005:11:348-51.

16. Skaife P, Lee S, Ramadwar M, Maitra D, Edwardson KF. Intestinal perforation as a presentation of Wegener's granulomatosis. Hosp Med. 2000;61:286-7.

17. Srinivasan U, Coughlan RJ. Small intestinal perforation complicating Wegener's granulomatosis. Rheumatology (Oxford). 1999;38:289-90.

18. Storesund B, Gran JT, Koldingsnes W. Severe intestinal involvement in Wegener's granulomatosis: report of two cases and review of the literature. Br J Rheumatol. 1998:37:387-90.

19. Tokuda M, Kurata N, Daikuhara H, Akisawa M, Onishi I, Asano T, Kobayashi S, Ohmori M, Irino S. Small intestinal perforation in Wegener's granulomatosis. J Rheumatol. 1989;16:547-9.

20. Geraghty J, Mackay IR, Smith DC. Intestinal perforation in Wegener's granulomatosis. Gut. 1986;27:450-1. 
21. Mcnabb WR, Lennox MS, Wedzicha JA. Small intestinal perforation in Wegener's granulomatosis. Postgrad Med J. 1982;58:123-5.

22. Comarmond C, Cacoub P. Granulomatosis with polyangiitis (Wegener): clinical aspects and treatment. Autoimmun Rev. 2014;13:1121-5.

23. Cornejo A, Bohnenblust M, Harris C, Abrahamian GA. Intestinal perforation associated with rituximab therapy for post-transplant lymphoproliferative disorder after liver transplantation. Cancer Chemother Pharmacol. 2009;64: 857-60.

24. Kutsch E, Kreiger P, Consolini D, Furuya KN. Colonic perforation after rituximab treatment for posttransplant lymphoproliferative disorder. J Pediatr Gastroenterol Nutr. 2013;56:e41.

\section{Publisher's Note}

Springer Nature remains neutral with regard to jurisdictional claims in published maps and institutional affiliations.

\section{Submit your manuscript to a SpringerOpen ${ }^{\circ}$ journal and benefit from:}

- Convenient online submission

- Rigorous peer review

- Open access: articles freely available online

- High visibility within the field

- Retaining the copyright to your article

Submit your next manuscript at $\boldsymbol{\nabla}$ springeropen.com 